BMJ Open Sport \& Exercise Medicine

\section{Cycling but not walking to work or study is associated with physical fitness, body composition and clustered cardiometabolic risk in young men}

To cite: Vaara JP, Vasankari T, Fogelholm M, et al. Cycling but not walking to work or study is associated with physical fitness, body composition and clustered cardiometabolic risk in young men. BMJ Open Sport \& Exercise Medicine 2020;6:e000668. doi:10.1136/ bmjsem-2019-000668

Accepted 6 February 2020
Check for updates

(c) Author(s) (or their employer(s)) 2020. Re-use permitted under CC BY-NC. No commercial re-use. See rights and permissions. Published by BMJ

${ }^{1}$ The Department of Leadership and Military Pedagogy, National Defence University, Helsinki, Finland

${ }^{2}$ UKK Institute for Health Promotion Research, Tampere, Finland

${ }^{3}$ Department of Food and Nutrition, University of Helsinki, Helsinki, Finland

${ }^{4}$ Training Division, Defence Command, Finnish Defence Forces, Helsinki, Finland ${ }^{5}$ University of Jyväskylä, Faculty of Sports and Health Sciences, Jyvaskyla, Finland

Correspondence to Dr Jani P Vaara; jani.vaara@mil.fi

\section{ABSTRACT}

Introduction Active commuting is an inexpensive and accessible form of physical activity and may be beneficial to health. The aim of this study was to investigate the association of active commuting and its subcomponents, cycling and walking, with cardiometabolic risk factors, physical fitness and body composition in young men. Methods Participants were 776 Finnish young $(26 \pm 7$ years), healthy adult men. Active commuting was measured with self-report. Waist circumference was measured and body mass index (BMI) calculated. Aerobic fitness was measured with bicycle ergometer and muscular fitness with maximal leg and bench press, situps, push-ups and standing long jump. Cardiometabolic risk factors were analysed from blood samples and selected variables (glucose, insulin, triglycerides, highdensity lipoprotein cholesterol, low-density lipoprotein cholesterol, as well as systolic and diastolic blood pressure) were further converted to z-score to form clustered cardiometabolic risk.

Results A total of $24 \%$ used active commuting consisting of $10 \%$ of walkers and $14 \%$ of cyclists. After adjustments for age, smoking, time of year, leisuretime and occupational physical activities, cycling was inversely associated with the clustered cardiometabolic risk ( $\beta=-0.11,95 \% \mathrm{Cl}-0.22$ to -0.01 ), while walking was not ( $\beta=-0.04,95 \% \mathrm{Cl}-0.16$ to 0.08 ). However, further adjustment for waist circumference attenuated the associations to non-significant. Moreover, cycling but not walking was inversely associated with BMI, waist circumference and maximal strength, while a positive association was observed with aerobic fitness $(p<0.05)$. Conclusion This study shows that cycling to work or study has beneficial associations to clustered cardiometabolic risk, body composition and aerobic fitness in young, healthy adult men.

\section{INTRODUCTION}

Lack of physical activity has shown to be associated with morbidity and premature mortality. ${ }^{1}$ One of physical activity domains, active commuting may provide large potential to increase physical activity because it is an accessible and relatively cheap alternative for
What are the new findings

Cycling to work or study was inversely associated with clustered cardiometabolic risk in young, healthy men.

- Cycling to work or study was positively associated with cardiorespiratory fitness and inversely with body composition in young, healthy men.

- Walking to work or study was not associated with physical fitness, body composition or clustered cardiometabolic risk in young, healthy men.

many individuals. In addition, it can be integrated into everyday life especially for those not interested or motivated to engaging in leisure-time physical activity.

The first large-scale study regarding active commuting and health was conducted by Andersen et al who showed in 20000 subjects that cycling to work was associated with a $28 \%$ decrease in mortality. ${ }^{2}$ Nevertheless, previous cross-sectional studies have observed conflicting results regarding cardiovascular risk factors, such as blood pressure, cholesterols and fasting glucose. ${ }^{3}$ Nevertheless, clustering of cardiovascular disease (CVD) risk factors has been observed to inversely associate with active commuting. ${ }^{45}$

In addition to physical activity and its components alone, physical fitness and body composition have independent and mediating effects regarding cardiometabolic health. ${ }^{6}$ Therefore, it is of interest to evaluate the associations between active commuting and fitness as well as body composition. Recent results from cross-sectional studies have shown that active commuting is inversely associated with body mass index (BMI) and body fat percentage $(\mathrm{BF} \%)$ in adult populations, ${ }^{78}$ whereas physical fitness has been less studied in adults. The few previous cross-sectional studies show positive associations between active commuting and 
cardiorespiratory fitness, whereas muscular fitness variables show non-significant findings. ${ }^{59}$

The associations and responses in the outcomes regarding active commuting can be different for walking and cycling as evidenced in some of the earlier studies favouring cycling compared with walking (eg, see previous works $^{10-12}$ ). Therefore, the primary aim of the present study was not only to compare fitness, body composition and cardiometabolic risk factors between active and passive commuting but also to assess more specifically associations of walking and cycling as separate entities.

\section{METHODS}

\section{Patient and public involvement}

The present cross-sectional study includes no patient and public involvement. Participants were 776 young (age $26 \pm 7$ years.) adult Finnish men, who were invited in the military refresher training. The call up to military refresher training and information about the study plan for participants were sent to participants 5 months before commencement of the study, which was carried out in seven different measurement sessions in 2015 (from May until November). The study protocol was explained in detail to the participants before they gave their written consent. This work was supported by The Scientific Advisory Board for Defence, Finland; National Defence Foundation, Finland and Support Foundation of the Finnish Defence Forces. Strengthening the Reporting of Observational Studies in Epidemiology (STROBE) crosssectional reporting guidelines have been applied in this study. ${ }^{13}$

Altogether, 1106 men were called up and 823 could participate in the military refresher training (response rate $74 \%$ ). Among those men who participated in the military refresher training, 32 refused to take part in the study (response rate 96\%). There were 15 women who participated in the study but are not included in these analyses. Due to some missing values in the outcomes, the total study sample was 749 . The study sample was compared with corresponding cohorts of Finnish men aged 20-30 years old in the national register data (Statistics Finland) from the year 2014 for education and place of residence. Based on these analyses, in the current study sample, Northern and Southern Finland were slightly over-represented. In addition, the proportion of those participants who had studied 13 years or more was slightly over-represented. Taking into account these limitations, the present study sample can be considered to represent young adult Finnish men.

\section{Assessment of travel behaviour and background information}

A questionnaire was used to assess demographics, physical activity and active commuting behaviour. Transportation mode to work or study was assessed with a question: "What is your typical transport mode to work or school? Response options were car, train, bus or tram, walking, cycling or other modes. The participants were only able to select one main mode of commuting. The commuting mode was stratified into active commuting as walking and cycling, whereas car, public and other modes were combined as passive travel behaviour, similar to previous studies. ${ }^{1012} 14$ In the present study, a questionnaire of commuting mode was similar to what previous studies have used. ${ }^{8}$ 10-12 Although, active commuting questionnaires have not been extensively validated, Panter et al showed that compared with objective measures (combined heart rate and movement sensors and global positioning system device), self-report instruments resulted in a 2 min overestimation for walking and a 1 min underestimation for cycling per trip. ${ }^{15}$ In addition, active commuting modes are mostly routine activities and therefore smaller recall bias may be present compared with other physical activity domains. ${ }^{16}$

Demographic variables consisted of age, marital status, employment status and smoking. Moreover, leisuretime and occupational physical activities (OPA, LTPA) were assessed by self-report and they were used as covariates in the statistical analysis. A detailed description of the questions has been reported earlier. ${ }^{5}$ Moreover, LTPA question has been validated against fitness in a previous study observing that weekly frequency of vigorous physical activity was positively associated with fitness. ${ }^{17}$

\section{Assessment of body composition, physical fitness and cardiometabolic risk factors}

Body composition. Body weight was measured to the nearest $0.1 \mathrm{~kg}$ and body height by a commercial scale to the nearest $0.1 \mathrm{~cm}$. BMI was also calculated. Waist circumference was measured by a tape measure at the level of iliac crest after exhaling. Physical fitness was assessed with several tests including cardiorespiratory fitness and muscular endurance and maximal strength. The participants performed the physical fitness tests in the following order: standing long jump, isometric maximal force, cardiorespiratory fitness and after minimum of $30 \mathrm{~min}$ rest muscular endurance tests were performed.

Cardiorespiratory fitness $\left(\mathrm{VO}_{2} \max \right)$ was determined using an indirect graded cycle ergometer test (Ergoline 800S, Ergoselect 100K, Ergoselect 200K, Bitz, Germany) until exhaustion. A detailed protocol information can be found elsewhere together with results of the high intraclass correlation of using this method. ${ }^{18}$

Muscular endurance tests consisted of push-ups and situps (repetitions/minute). There was a recovery period of 5 min between the tests. Standing long jump test was performed in the specifically designed gym mat. The warm-up lasted $10 \mathrm{~min}$ and consisted of callisthenics exercises, such as x-jumps, push-ups, sit-ups, squats, planks and countermovement jumps. The participants completed three trials each interspersed by a $1 \mathrm{~min}$ rest period. The performance was measured with $1 \mathrm{~cm}$ precision. Maximal isometric force was measured with horizontal bench and leg press (both regarded as tests for maximal strength) using a dynamometer. Detailed information about procedures can be found elsewhere. ${ }^{5}$ 
The cardiometabolic risk factors consisted of blood pressure, serum lipids and plasma glucose, insulin and HbA1C. Furthermore, inflammatory factors, such as interleukin-6 (IL-6), C reactive protein (CRP) and adiponectin, were measured. Blood pressure was recorded three times at 2 min intervals in a seated position using an automatic blood pressure device (Omron M6 Comfort, Netherlands). In the analysis, a mean of the two lowest values was used. Blood samples were drawn from the ulnar vein using Terumon Venosafe (Terumo Europe, Leuven, Belgium) and were centrifuged at the speed of $3500 \mathrm{rpm}$. Glucose, insulin, HbA1C, serum high-density lipoprotein (HDL)cholesterol and triglycerides (TGs) were analysed by the Konelab 20 XTi -device (Thermo Electron Co, Vantaa, Finland) and the isolated low-density lipoprotein (LDL)cholesterol fraction was used for direct measurement of LDL-cholesterol (CHOD-PAP method). Moreover, apolipoprotein (Apo) Ala and A1b and their ratio were analysed. The ranges for TGs, HDL-cholesterol and LDLcholesterol assays were $0.05-11.0,0.16-0.84,0.09-11.0$ $\mathrm{mmol} / \mathrm{L}$, respectively, and for Apo A1 and B 0.1-11.0 and $0.1-11.0$, respectively. The ranges for glucose, insulin and $\mathrm{HbAlc}$ were $0.3-40.0 \mathrm{mmol} / \mathrm{L}, 2.0-300.0 \mathrm{IU} / \mathrm{mL}$ and $20.0-150.0 \mathrm{mmol} / \mathrm{mol}$, respectively. Moreover, the ranges for adiponectin, IL-6 and for CRP were 5.0-150.0 $\mathrm{ng} / \mathrm{mL}, 2.0-60.0 \mathrm{pg} / \mathrm{mL}$ and $0.2-3780.0 \mathrm{mg} / \mathrm{L}$, respectively. Intra-assay and interassay coefficients of variance were $1.0 \%$ and $2.5 \%$ for TG, $1.1 \%$ and $2.3 \%$ for LDL, and $0.5 \%$ and $7.6 \%$ for HDL, respectively, and for Apo A1 and $\mathrm{B} 2.7 \%$ and $4.6 \%$ and $1.6 \%$ and $3.4 \%$, respectively. Intra-assay and interassay coefficients of variance were $1.0 \%$ and $1.6 \%, 4.0 \%$ and $4.9 \%$, and $1.6 \%$ and $2.8 \%$ for glucose, insulin and $\mathrm{HbA1c}$, respectively. Intra-assay and interassay coefficients of variance for adiponectin, IL-6 and CRP were $4.4 \%$ and $5.8 \%, 4.5 \%$ and $5.3 \%$, and $4.7 \%$ and $7.1 \%$, respectively.

In addition, a continuous clustered cardiometabolic risk, similar to earlier studies, ${ }^{519}$ was used in the current study. The score consisted of glucose, insulin, TGs, HDL-cholesterol, LDL-cholesterol, as well as systolic and diastolic blood pressure. First, the values of each cardiometabolic risk factor were transformed to z-scores. HDL-cholesterol was inverted before being included in the risk score. The continuous clustered cardiometabolic risk (range -1.17 to +3.11 ) was calculated from the mean of z-score values of all cardiometabolic risk factors.

\section{Statistical analysis}

Data were analysed with IBM SPSS Statistics V.22.0.0.0. Descriptive statistics as frequencies, means, SD and 95\% CI were calculated. Normal distribution was tested with Kolmogorov-Smirnoff. Those variables that were not normally distributed were log-transformed (HDL, LDL, TGs, Apo-A1, Apo-B, Apo-A1/Apo-B ratio, glucose, insulin, HbAlc, adiponectin, IL-6 and CRP). Analysis of covariance and nominal regression analysis were conducted for exploring the associations between passive and active commuting including its subgroups (cycling and walking) with body composition, physical fitness and cardiometabolic risk factors. Besides the adjustments of age and smoking in the regression models, leisure-time physical activity and occupational physical activity were adjusted because of their interactions. The proportion of those engaging to leisure-time physical activity three or more times per week (high LTPA group) were as follows: $51 \%$ among cyclists, $43 \%$ among walkers and $38 \%$ among passive commuters $(\mathrm{p}=0.074)$. In addition, the proportions of those with sedentary or light occupational physical activity (low OPA group) were 52\% among cyclists, 58\% among walkers and $41 \%$ among passive commuters $(\mathrm{p}=0.017)$. In addition, measurement site was used as a covariate to reflect seasonal variation in active commuting because measurements were conducted starting from May until November including different seasons. Furthermore, additional model included also waist circumference as an adjusted variable for clustered cardiometabolic risk.

\section{RESULTS}

\section{Participants characteristics}

The demographics and travel modes to work or study are presented in table 1 and the means and SD in body composition, physical fitness and cardiometabolic risk factor variables in table 2. Twenty-four per cent engaged to active commuting consisting of $10 \%$ walkers and $14 \%$ cyclists (table 1 ).

\section{Associations of active commuting with physical fitness and body composition}

After adjustments for age, measurement site, smoking, leisure-time and occupational physical activities, active commuting group had higher aerobic fitness but lower push-up performance and maximal strength of the lower and upper extremities compared with passive travellers $(p<0.05)$. In addition, cycling group had higher maximal oxygen uptake $(p<0.05)$, whereas the walking group had lower maximal oxygen uptake and maximal force of lower extremities compared with passive travellers $(p<0.05)$. After the adjustments, cycling group had lower waist circumference and BMI $(\mathrm{p}<0.05)$, whereas no other differences were found between the groups (table 3).

\section{Associations of active commuting with cardiometabolic risk factors}

Although the clustered cardiometabolic risk was not associated with active commuting in general $(\beta=-0.08,95 \%$ CI -0.17 to $0.01, p=0.059)$ or with walking $(\beta=-0.04,95 \%$ CI -0.16 to $0.08, p=0.507$ ), a significant inverse association with cycling was observed $(\beta=-0.11,95 \%$ CI -0.22 to -0.01 , $\mathrm{p}=0.044$ ) adjusted for age, measurement site, smoking, leisure-time and occupational physical activity. However, the association was attenuated to non-significant after further adjustment for waist circumference. After the adjustments for age, measurement site, smoking, leisuretime and occupational physical activity, no differences were observed in single cardiometabolic or inflammatory 


\begin{tabular}{lrr}
$\begin{array}{l}\text { Table } 1 \quad \text { Demographic and baseline characteristics in travel } \\
\text { parameters in the study sample }\end{array}$ & \multicolumn{1}{c}{$\%$} \\
\hline Characteristics & $\mathbf{n}$ \\
\hline Smoking & 25.9 & 194 \\
\hline Smokers & & \\
\hline Marital status & 44.6 & 334 \\
\hline Married/partnered & 3.2 & 24 \\
\hline Divorced/widowed & 52.2 & 391 \\
\hline Never married/single & & \\
\hline Education & 3.3 & 25 \\
\hline S9 years & 33.6 & 252 \\
\hline 10-12 years & 41.9 & 314 \\
\hline 13-15 years & 21.1 & 158 \\
\hline 16 years & & \\
\hline Employment status & 69.3 & 519 \\
\hline Employed & 25.0 & 187 \\
\hline Student & 5.7 & 43 \\
\hline House husband/unemployed & & \\
\hline Mode of travel to work or study & 24.1 & 181 \\
\hline Active commuting & 10.1 & 76 \\
\hline Walking & 14.0 & 105 \\
\hline Cycling & 75.9 & 568 \\
\hline Passive travel & 27.8 & 223 \\
\hline Leisure-time physical activity & 46.4 & 223 \\
\hline Low & 25.9 & 303 \\
\hline Moderate & & \\
\hline High & 27.8 & 204 \\
\hline Occupational physical activity & 46.1 & 341 \\
\hline Mow & 26.1 & 190 \\
\hline High & & \\
\hline
\end{tabular}

risk factors between any of the groups, although borderline significances were observed for cycling and walking compared with passive travellers in insulin concentration $(\mathrm{p}=0.053, \mathrm{p}=0.061$, respectively) (table 4$)$. Moreover, the regression analysis showed similar non-significant associations and additional adjustment for waist circumference did not change these results.

\section{DISCUSSION}

The main results of the present study indicate that cycling was inversely associated with the clustered cardiometabolic risk. Moreover, cycling but not walking to work or study was inversely associated with body composition and positively with aerobic fitness.

In previous cross-sectional studies, conflicting results have been observed regarding blood pressure, cholesterols and fasting glucose (eg, see previous work $^{3}$ ). Our previous study with a similar study sample showed that active commuting combining walkers and cyclists
Table 2 The baseline characteristics in physical fitness, cardiometabolic risk factors and inflammatory factors

\begin{tabular}{lcc|}
\hline & Mean \pm SD & $95 \% \mathbf{C l}$ \\
\hline Age (years) & $26 \pm 7$ & 26 to 27 \\
\hline $\begin{array}{l}\text { Body composition } \\
\quad \text { Body weight }(\mathrm{kg})\end{array}$ & $81.3 \pm 14.9$ & 80.2 to 82.3 \\
\hline Body mass index & $25.2 \pm 4.1$ & 24.9 to 25.5 \\
$\begin{array}{l}\text { Waist circumference } \\
(\mathrm{cm})\end{array}$ & $87.4 \pm 11.1$ & 86.6 to 88.2 \\
\hline
\end{tabular}

Physical fitness

\begin{tabular}{|c|c|c|}
\hline $\mathrm{VO}_{2 \max }(\mathrm{mL} / \mathrm{min} / \mathrm{kg})$ & $41.1 \pm 7.8$ & 40.5 to 41.6 \\
\hline Standing long jump (cm) & $227 \pm 26$ & 225 to 229 \\
\hline Sit-ups (reps/min) & $35 \pm 12$ & 34 to 36 \\
\hline Push-ups (reps/min) & $28 \pm 14$ & 27 to 29 \\
\hline $\begin{array}{l}\text { Maximal strength in } \\
\text { bench press }(\mathrm{N})\end{array}$ & $871 \pm 216$ & 856 to 887 \\
\hline $\begin{array}{l}\text { Maximal strength in leg } \\
\text { extension }(\mathrm{N})\end{array}$ & $3394 \pm 933$ & 3327 to 3461 \\
\hline \multicolumn{3}{|l|}{ Cardiometabolic risk factors } \\
\hline $\begin{array}{l}\text { Systolic blood pressure } \\
(\mathrm{mm} \mathrm{Hg})\end{array}$ & $123.4 \pm 11.8$ & 122.6 to 124.3 \\
\hline $\begin{array}{l}\text { Diastolic blood pressure } \\
(\mathrm{mm} \mathrm{Hg})\end{array}$ & $74.5 \pm 9.2$ & 73.8 to 75.1 \\
\hline $\begin{array}{l}\text { HDL-cholesterol } \\
(\mathrm{mmol} / \mathrm{L})\end{array}$ & $1.41 \pm 0.33$ & 1.39 to 1.43 \\
\hline $\begin{array}{l}\text { LDL-cholesterol } \\
\text { (mmol/L) }\end{array}$ & $2.76 \pm 0.81$ & 2.70 to 2.81 \\
\hline Triglycerides (mmol/L) & $1.12 \pm 0.81$ & 1.07 to 1.17 \\
\hline Apo-A1 (g/L) & $1.52 \pm 0.27$ & 1.50 to 1.54 \\
\hline Apo-B ( $\mu g / L)$ & $0.80 \pm 0.22$ & 0.78 to 0.81 \\
\hline Apo-A/Apo-B ratio & $2.04 \pm 0.66$ & 1.99 to 2.09 \\
\hline $\begin{array}{l}\text { Plasma glucose } \\
(\mathrm{mmol} / \mathrm{L})\end{array}$ & $4.91 \pm 0.75$ & 4.86 to 4.96 \\
\hline Insulin (mIU/L) & $4.85 \pm 4.05$ & 4.57 to 5.14 \\
\hline $\mathrm{HbA} 1 \mathrm{c}(\mathrm{mmol} / \mathrm{mol})$ & $31.47 \pm 3.05$ & 31.26 to 31.70 \\
\hline $\begin{array}{l}\text { Clustered } \\
\text { cardiometabolic risk }\end{array}$ & $0.003 \pm 0.571$ & -0.04 to 0.04 \\
\hline \multicolumn{3}{|l|}{ Inflammatory factors } \\
\hline Adiponectin $(\mu \mathrm{g} / \mathrm{mL})$ & $6.50 \pm 2.55$ & 6.32 to 6.68 \\
\hline IL-6 (pg/mL) & $1.16 \pm 1.46$ & 1.06 to 1.26 \\
\hline $\mathrm{CRP}(\mathrm{mg} / \mathrm{L})$ & $1.59 \pm 3.83$ & 1.32 to 1.86 \\
\hline
\end{tabular}

CRP, C reactive protein ; HDL, high-density lipoprotein; IL-6, interleukin-6; LDL, low-density lipoprotein.

together and including running errands was inversely associated with the clustered cardiovascular risk but not with single risk factors. ${ }^{5}$ Similarly, Kwaśniewska et al found no association between active commuting and single CVD risk factors however, when CVD risk factors were clustered together as metabolic syndrome, a higher prevalence of the syndrome in the low active commuting group was observed compared with the high group. ${ }^{4}$ In 
Table 3 Group comparisons (mean \pm SE) between passive travel and active commuting (walking, cycling) in body composition, physical fitness and cardiometabolic risk factors adjusted for age, smoking, measurement site, leisure-time and occupational physical activity

\begin{tabular}{|c|c|c|c|c|}
\hline & Passive travel $(n=568)$ & Active commuting ( $n=181)$ & Cycling ( $n=105)$ & Walking $(n=76)$ \\
\hline \multicolumn{5}{|l|}{ Body composition } \\
\hline Body mass (kg) & $82.2 \pm 15.1(81.0-83.5)$ & $79.0 \pm 14.2(76.9-81.1)$ & $77.4 \pm 13.3(74.8-80.1)^{\star}$ & $81.1 \pm 15.2(77.6-84.6)$ \\
\hline Body mass index & $25.3 \pm 0.2(24.9-25.7)$ & $24.6 \pm 0.3(24.0-25.3)$ & $24.4 \pm 0.4(23.5-25.2)^{*}$ & $25.0 \pm 0.5(24.1-26.0)$ \\
\hline Waist circumference (cm) & $87.9 \pm 0.50$ (86.9-88.9) & $86.2 \pm 0.87(84.4-87.9)$ & $85.3 \pm 1.1(83.1-87.5)^{\star}$ & $87.4 \pm 1.3(84.8-89.9)$ \\
\hline \multicolumn{5}{|l|}{ Physical fitness } \\
\hline $\mathrm{VO}_{2} \max (\mathrm{mL} / \mathrm{kg} / \mathrm{min})$ & $39.8 \pm 0.3(39.2-40.5)$ & $41.8 \pm 0.59(40.67-42.98)^{\star \star \star}$ & $44.1 \pm 0.7(42.7-45.6)^{\star \star \star}$ & $38.6 \pm 0.8(36.9-40.3) \dagger$ \\
\hline Standing long jump (cm) & $226.9 \pm 1.2(224.5-229.2)$ & $223.5 \pm 2.10(219.3-227.6)$ & $224.9 \pm 2.7(219.7-230.2)$ & $221.4 \pm 3.1(215.3-227.5)$ \\
\hline Sit-ups (reps/min) & $33.5 \pm 0.5(32.5-34.5)$ & $34.8 \pm 0.9(33.1-36.5)$ & $35.2 \pm 1.1(33.0-37.3)$ & $34.4 \pm 1.3(31.9-36.9)$ \\
\hline Push-ups (reps/min) & $27.7 \pm 0.6(26.6-28.9)$ & $25.4 \pm 1.0(23.3-27.4)^{*}$ & $25.6 \pm 1.3(23.1-28.2)$ & $25.0 \pm 1.5(22.0-27.9)$ \\
\hline $\begin{array}{l}\text { Maximal strength in } \\
\text { bench press }(\mathrm{N})\end{array}$ & $3425 \pm 39(3256-3424)$ & $3315 \pm 70(3178-3452)^{*}$ & $3087 \pm 94(2903-3271)^{\star}$ & $3254 \pm 109$ (3041-3468) \\
\hline $\begin{array}{l}\text { Maximal strength in leg } \\
\text { extension }(\mathrm{N})\end{array}$ & $869 \pm 10(850-888)$ & $805 \pm 17(771-838)^{\star \star \star}$ & $775 \pm 21(733-817)^{\star \star \star}$ & $847 \pm 25$ (798-895)‡ \\
\hline \multicolumn{5}{|l|}{ Cardiometabolic risk factors } \\
\hline $\begin{array}{l}\text { Systolic blood pressure } \\
(\mathrm{mm} \mathrm{Hg})\end{array}$ & $123.9 \pm 0.6(122.8-125.0)$ & $122.4 \pm 1.0(120.4-124.3)$ & $122.3 \pm 1.2(119.9-124.8)$ & $122.3 \pm 1.4(119.5-125.1)$ \\
\hline $\begin{array}{l}\text { Diastolic blood pressure } \\
(\mathrm{mm} \mathrm{Hg})\end{array}$ & $75.1 \pm 0.4(74.2-75.9)$ & $74.6 \pm 0.7(73.1-76.0)$ & $74.3 \pm 0.9(72.5-76.1)$ & $74.9 \pm 1.1(72.8-77.0)$ \\
\hline $\begin{array}{l}\text { HDL-cholesterol } \\
\text { (mmol/L) }\end{array}$ & $1.39 \pm 0.02(1.36-1.42)$ & $1.41 \pm 0.03(1.35-1.46)$ & $1.39 \pm 0.04(1.32-1.45)$ & $1.44 \pm 0.04(1.36-1.51)$ \\
\hline LDL-cholesterol (mmol/L) & $2.72 \pm 0.04(2.65-2.80)$ & $2.65 \pm 0.06(2.52-2.78)$ & $2.61 \pm 0.08(2.45-2.78)$ & $2.71 \pm 0.10(2.52-3.00)$ \\
\hline Triglycerides (mmol/L) & $1.14 \pm 0.03(1.09-1.20)$ & $1.11 \pm 0.05(1.01-1.20)$ & $1.11 \pm 0.06(0.98-1.23)$ & $1.11 \pm 0.07(0.97-1.25)$ \\
\hline Apo-A (g/L) & $0.40 \pm 0.01(0.38-0.41)$ & $0.42 \pm 0.01(0.39-0.44)$ & $0.41 \pm 0.02(0.38-0.44)$ & $0.43 \pm 0.02(0.39-0.46)$ \\
\hline Apo-B ( $\mu \mathrm{g} / \mathrm{L})$ & $0.79 \pm 0.01(0.77-0.81)$ & $0.80 \pm 0.01(0.77-0.83)$ & $0.79 \pm 0.02(0.75-0.84)$ & $0.81 \pm 0.03(0.76-0.86)$ \\
\hline Apo-A/Apo-B ratio & $2.05 \pm 0.03(1.99-2.11)$ & $2.08 \pm 0.05(1.97-2.18)$ & $2.03 \pm 0.07(1.90-2.16)$ & $2.13 \pm 0.08(1.99-2.28)$ \\
\hline Plasma glucose (mmol/L) & $4.89 \pm 0.02(4.85-4.94)$ & $4.83 \pm 0.04(4.74-4.92)$ & $4.82 \pm 0.05(4.73-4.92)$ & $4.72 \pm 0.05(4.61-4.83)$ \\
\hline Insulin (mIU/L) & $5.07 \pm 4.35(4.70-5.43)$ & $4.41 \pm 3.07(3.96-4.87)$ & $4.28 \pm 3.33(3.50-5.05)$ & $4.52 \pm 2.87(3.95-5.08)$ \\
\hline $\mathrm{HbA} 1 \mathrm{c}(\mathrm{mmol} / \mathrm{mol})$ & $31.55 \pm 0.15(31.27-32.25)$ & $31.47 \pm 0.25$ (30.99-31.95) & $31.59 \pm 0.32(30.96-32.23)$ & $31.53 \pm 0.37(30.80-32.25)$ \\
\hline \multicolumn{5}{|l|}{ Inflammatory factors } \\
\hline Adiponectin (mmol/L) & $6.34 \pm 0.12(6.10-6.59)$ & $6.43 \pm 0.22(6.01-6.85)$ & $6.33 \pm 0.28(5.79-6.87)$ & $6.57 \pm 0.31(5.95-7.18)$ \\
\hline IL-6 (pg/mL) & $1.17 \pm 0.07(1.04-1.31)$ & $1.32 \pm 0.12(1.08-1.56)$ & $1.34 \pm 0.16(1.03-1.64)$ & $1.29 \pm 0.18(0.93-1.65)$ \\
\hline CRP $(p g / m L)$ & $1.60 \pm 0.16(1.27-1.92)$ & $1.68 \pm 0.33(1.04-2.32)$ & $1.46 \pm 0.39(0.70-2.22)$ & $1.52 \pm 0.46(0.61-2.42)$ \\
\hline
\end{tabular}

${ }^{*} \mathrm{p}<0.05$ significant difference compared with passive travel; ${ }^{* *} \mathrm{p}<0.001$ significant difference compared with passive travel. $\dagger p<0.001$ significant difference compared with cycling.

$\ddagger \dagger p<0.05$ significant difference compared with cycling.

Apo-A1, apolipoprotein A1; Apo-A, apolipoprotein A; Apo-B, apolipoprotein B; CRP, C reactive protein; HDL, high-density lipoprotein; IL-6, interleukin-6; LDL, low-density lipoprotein.

line with the present study, Andersen et al also showed in their prospective study that cycling, but not walking to school, was inversely associated with CVD risk factors in children. ${ }^{14}$

The exercise intensity in cycling is higher compared with walking ${ }^{20}$ and, therefore, may partly explain the difference observed between cycling and walking. Moreover, the current study sample consisted of rather fit, lean, healthy young men and, therefore, it may be speculated that no association was observed for active commuting and individual CVD risk factors, as well as for inflammatory factors. It may be that associations exist more commonly in different study samples, such as individuals with obesity and sedentary individuals. In direct support of this, Gram et alreported in their randomised controlled trial (RCT) study that overweight and obese individuals who cycled 6 months to their work decreased the concentration of CRP, however, not that of fibrinogen. ${ }^{21}$ As inflammatory factors are closely related to fat mass it may, however, be interpreted that the decrease in CRP in the study by Gram et al was, at least partially, mediated by modest weight loss $(1.8 \mathrm{~kg}) .^{21}$

Body mass, BMI and waist circumference were all inversely associated with cycling but not walking to work or study in the present study. The majority of previous cross-sectional studies report inverse associations between 
Table 4 Regression analysis (standardised beta-coefficients and $95 \% \mathrm{Cl}$ ) of active commuting and its subgroups in body composition, physical fitness and cardiometabolic risk factors adjusted for age, smoking, measurement site, leisure-time and occupational physical activity

\begin{tabular}{|c|c|c|c|}
\hline & Active commuting ( $n=568)$ & Cycling (n=105) & Walking $(n=76)$ \\
\hline \multicolumn{4}{|l|}{ Body composition } \\
\hline Body mass (kg) & $-2.15(-4.69$ to 0.39$)$ & $-3.62(-6.77 \text { to }-0.47)^{\star}$ & $-0.15(-3.73$ to 3.44$)$ \\
\hline Body mass index & $-0.66(-1.36$ to 0.05$)$ & $-0.94(-1.82 \text { to }-0.07)^{*}$ & $-0.27(-1.26$ to 0.73$)$ \\
\hline Waist circumference $(\mathrm{cm})$ & $-1.72(-3.55$ to 0.10$)$ & $-2.57(-4.82 \text { to }-0.33)^{*}$ & $-0.52(-3.12$ to 2.08 \\
\hline \multicolumn{4}{|l|}{ Physical fitness } \\
\hline $\mathrm{VO}_{2} \max (\mathrm{mL} / \mathrm{kg} / \mathrm{min})$ & $2.01(0.77 \text { to } 3.24)^{\star \star \star}$ & $4.31(2.81 \text { to } 5.80)^{\star \star \star}$ & $-1.25(-2.96$ to 0.49$)$ \\
\hline Standing long jump (cm) & $-3.39(-7.79$ to 1.01$)$ & $-1.91(-7.34$ to 3.52$)$ & $\begin{array}{l}-5.45(-11.70 \text { to } \\
0.81)\end{array}$ \\
\hline Sit-ups (reps/min) & $1.34(-0.47$ to 3.16$)$ & $1.68(-0.56$ to 3.91$)$ & $0.87(-1.71$ to 3.46$)$ \\
\hline Push-ups (reps/min) & $-2.38(-4.53 \text { to }-0.23)^{*}$ & $-2.12(-4.76$ to 0.53$)$ & $-2.75(-5.81$ to 0.32$)$ \\
\hline Maximal strength in bench press $(\mathrm{N})$ & $-18.35(-33.88 \text { to }-2.83)^{\star}$ & $-25.28(-44.39 \text { to }-6.16)^{\star}$ & $\begin{array}{l}-8.57(-30.68 \text { to } \\
13.54)\end{array}$ \\
\hline Maximal strength in leg extension $(\mathrm{N})$ & $-6.41(-9.97 \text { to }-2.85)^{\star \star *}$ & $-9.37(-13.73 \text { to }-5.00)^{\star \star *}$ & $-2.24(-7.29$ to 2.82$)$ \\
\hline \multicolumn{4}{|l|}{ Cardiometabolic risk factors } \\
\hline Clustered cardiometabolic risk & $-0.08(-0.17$ to 0.01$)$ & $-0.11(-0.22 \text { to }-0.01)^{*}$ & $-0.04(-0.16$ to 0.08$)$ \\
\hline Systolic blood pressure $(\mathrm{mm} \mathrm{Hg})$ & $-1.61(-3.65$ to 0.43$)$ & $-1.59(-4.10$ to 0.92$)$ & $-1.63(-4.54$ to 1.27$)$ \\
\hline Diastolic blood pressure $(\mathrm{mm} \mathrm{Hg})$ & $-0.53(-2.02$ to 1.01$)$ & $-0.72(-2.59$ to 1.15$)$ & $-1.99(-2.36$ to 1.96$)$ \\
\hline HDL-cholesterol (mmol/L) & $0.02(-0.04$ to 0.08$)$ & $-0.01(-0.07$ to 0.07$)$ & $0.05(-0.03$ to 0.13$)$ \\
\hline LDL-cholesterol (mmol/L) & $-0.07(-0.21$ to 0.07$)$ & $-0.11(-0.28$ to 0.06$)$ & $-0.01(-0.21$ to 0.18$)$ \\
\hline Triglycerides (mmol/L) & $-0.04(-0.14$ to 0.07$)$ & $-0.04(-0.17$ to 0.09$)$ & $-0.03(-0.18$ to 0.11$)$ \\
\hline Apo-A (g/L) & $0.02(-0.01$ to 0.05$)$ & $0.01(-0.02$ to 0.05$)$ & $0.03(-0.01$ to 0.07$)$ \\
\hline Apo-B $(\mu \mathrm{g} / \mathrm{L})$ & $0.01(-0.03$ to 0.06$)$ & $0.01(-0.05$ to 0.07$)$ & $0.02(-0.05$ to 0.08$)$ \\
\hline Apo-A/Apo-B ratio & $0.01(-0.05$ to 0.06$)$ & $-0.02(-0.15$ to 0.12$)$ & 0.09 (-0.07 to 0.24$)$ \\
\hline Plasma glucose (mmol/L) & $-0.06(-0.15$ to 0.03$)$ & $-0.01(-0.03$ to 0.01$)$ & $-0.02(-0.05$ to 0.01$)$ \\
\hline Insulin (mlU/L) & $-0.09(-0.25$ to -0.07$)$ & $-0.22(-0.44$ to 0.01$)$ & $0.01(-0.19$ to 0.21$)$ \\
\hline $\mathrm{HbA1c}(\mathrm{mmol} / \mathrm{mol})$ & $-0.23(-0.75$ to 0.28$)$ & $-0.41(-1.05$ to 0.23$)$ & $0.01(-0.73$ to 0.73$)$ \\
\hline \multicolumn{4}{|l|}{ Inflammatory factors } \\
\hline Adiponectin (mmol/L) & $0.01(-0.06$ to 0.08$)$ & $0.01(-0.08$ to 0.09$)$ & $0.02(-0.08$ to 0.11$)$ \\
\hline IL-6 (pg/mL) & $0.14(-0.12$ to 0.40$)$ & $0.13(-0.13$ to 0.38$)$ & $-0.06(-0.36$ to 0.23$)$ \\
\hline $\mathrm{CRP}(\mathrm{pg} / \mathrm{mL})$ & $-0.07(-0.76$ to 0.61$)$ & $-0.06(-0.34$ to 0.21$)$ & $0.07(-0.24$ to 0.38$)$ \\
\hline
\end{tabular}

${ }^{*} \mathrm{p}<0.05$ significant difference compared with passive travel; ${ }^{* \star} \mathrm{p}<0.001$ significant difference compared with passive travel. Apo-A, apolipoprotein A; Apo-B, apolipoprotein B; CRP, C reactive protein; HDL, high-density lipoprotein; IL-6, interleukin-6; LDL, lowdensity lipoprotein.

active commuting and body weight ${ }^{19}$ and large observational studies from UK biobank data have revealed inverse associations with active commuting and BMI. ${ }^{78}$ A prospective study confirms that change from passive to more active commuting is associated with a reduction in BMI, ${ }^{22}$ and the results from the few RCT studies show that cycling to work reduces both body mass and/or body $\mathrm{fat}^{212324}$ and BMI but not fat-free mass. ${ }^{21} 24$

There are very few previous observational studies that have investigated active commuting including cycling and walking with physical fitness outcomes in adult populations. In our previous study, ${ }^{5}$ it was shown that active commuting, either by cycling or walking, to work or study, also including running errands, was positively associated with aerobic fitness. Similarly, Bopp et al reported in university students that active commuting was positively related to aerobic fitness. ${ }^{9}$ Furthermore, the very few RCT studies show beneficial effects of cycling to work on aerobic fitness. ${ }^{21} 23$

Due to cross-sectional study design causality cannot be determined and reverse causality, however, has to be taken into account in the present study. It may be that aerobically fitter individuals are more prone than their less fit counterparts to use active commuting as a means of transportation. Second, it is possible that individuals who have good inherited aerobic capacity are more 
prone to choose active commuting and this would also be reflected to lower maximal strength test results in cyclists. On the other hand, although there are not many previous intervention studies, the few studies do suggest a causal pathway between cycling to work and improvement of cardiorespiratory fitness. ${ }^{20} 212325$

In the present study, there were no differences in explosive force production of lower extremities measured as standing long jump between passive and active commuters and its subgroups. Similarly, maximal strength tests showed no differences in our previous study with active commuting including also running errands, although muscular endurance was higher in those ones with high active commuting level. ${ }^{5}$ On the other hand, Bopp et al reported no differences between active and passive commuters in muscular endurance or maximal strength in university students. ${ }^{9}$ Better muscular endurance test results in the present study may in part be related to the mode (60 s tests) of muscular tests since they require also aerobic component.

\section{Strengths and limitations}

The strength of the present study is the extensive measurements of objective measures of cardiometabolic risk factors, including inflammatory factors, and physical fitness as well as body composition measurements. However, the exposure outcome of commuting mode is self-reported and therefore may be less reliable. However, commuting mode is mostly a routine activity and therefore may include less limitations regarding recall bias. ${ }^{16}$ Furthermore, only a small overestimation of $2 \mathrm{~min}$ for walking and $1 \mathrm{~min}$ underestimation for cycling per trip has been observed for active commuting time. ${ }^{15}$ The main limitations of the present study are lack of data on active commuting frequency, volume and intensity, which all may play significant role on the outcome variables. Unfortunately, with this questionnaire we were not able to assess these details in either cycling or walking groups. Moreover, participants were only able to select one main mode of travel and as some individuals may switch between active and passive travel that is a limitation. Mixed-model travel options would have offered more insight in the current topic, and are therefore warranted in the future studies. In addition, time of year may influence on physical activity behaviour and therefore we attempted to adjust the analysis with time of year (measurement site). Most of the previous studies have assessed aerobic fitness by using cycle ergometer test, which could potentially favour cyclists compared with walkers. However, a previous study showed that mechanical efficiency was not better in cyclists compared with walkers in submaximal performance using direct measurement of oxygen uptake. ${ }^{10}$

\section{CONCLUSION}

In conclusion, the present study demonstrated that among young, healthy adult men cycling to work or study was inversely associated with clustered cardiometabolic risk and body composition, and positively with aerobic fitness. Similar associations were not evident for walking. Aerobic fitness and body composition are important mediators for cardiometabolic health and thereby their improvements induced by cycling to work or study may lead to cardioprotective effects in the long term. As an important dimension of total physical activity spectrum, cycling to work should further be promoted because cycling is rather inexpensive form of physical activity and therefore may be easily adopted by an individual. Practical applications may include also improvements in cycling infrastructure to make cycling more appealing choice of physical activity.

\section{Twitter Jani P Vaara @JaniVaara}

Acknowledgements The authors would like to thank all the personnel in the data collection and the participants for taking part in this study. We would like to acknowledge Elina Vaara for her work with the statistical analysis.

Contributors JPV, TV, MF, HK and HK conceived and designed the study. Elina Vaara and JPV analysed the data. JPV prepared the first draft of the manuscript. TV, MF, HK and HK made substantial contributions to interpreting the data, revising it critically for important intellectual content and have given approval of the final version to be submitted.

Funding This work was supported by The Scientific Advisory Board for Defence, Finland; National Defence Foundation, Finland and Support Foundation of the Finnish Defence Forces.

\section{Competing interests None declared.}

Patient consent for publication Not required.

Ethics approval The study protocol was explained in detail to the participants before they gave their written consent. The study was approved by the ethical committees of the University of Jyväskylä and the Central Finland Health Care District, as well as the Headquarters of the Finnish Defence Forces (AM5527).

Provenance and peer review Not commissioned; externally peer reviewed.

Data availability statement Data are available on reasonable request. The Finnish Defence Forces own and manage the data, which are available for researchers who meet the criteria for access to confidential data.

Open access This is an open access article distributed in accordance with the Creative Commons Attribution Non Commercial (CC BY-NC 4.0) license, which permits others to distribute, remix, adapt, build upon this work non-commercially, and license their derivative works on different terms, provided the original work is properly cited, appropriate credit is given, any changes made indicated, and the use is non-commercial. See: http://creativecommons.org/licenses/by-nc/4.0/.

\section{ORCID iD}

Jani P Vaara http://orcid.org/0000-0002-2346-4073

\section{REFERENCES}

1 Booth FW, Roberts CK, Thyfault JP, et al. Role of inactivity in chronic diseases: evolutionary insight and pathophysiological mechanisms. Physiol Rev 2017;97:1351-402.

2 Andersen LB, Schnohr P, Schroll M, et al. All-Cause mortality associated with physical activity during leisure time, work, sports, and cycling to work. Arch Intern Med 2000;160:1621-8.

3 Gordon-Larsen P, Boone-Heinonen J, Sidney S, et al. Active commuting and cardiovascular disease risk: the cardia study. Arch Intern Med 2009;169:1216-23.

4 Kwaśniewska M, Kaczmarczyk-Chałas K, Pikala M, et al. Commuting physical activity and prevalence of metabolic disorders in Poland. Prev Med 2010;51:482-7.

5 Vaara JP, Kyröläinen H, Fogelholm M, et al. Associations of leisure time, commuting, and occupational physical activity with physical fitness and cardiovascular risk factors in young men. $J$ Phys Act Health 2014;11:1482-91.

6 Grundy SM, Barlow CE, Farrell SW, et al. Cardiorespiratory fitness and metabolic risk. Am J Cardiol 2012;109:988-93. 
7 Flint E, Cummins S, Sacker A. Associations between active commuting, body fat, and body mass index: population based, cross sectional study in the United Kingdom. BMJ 2014;349:g4887.

8 Flint E, Cummins S. Active commuting and obesity in mid-life: crosssectional, observational evidence from UK Biobank. Lancet Diabetes Endocrinol 2016;4:420-35.

9 Bopp M, Bopp C, Schuchert M. Active transportation to and on campus is associated with objectively measured fitness outcomes among college students. J Phys Act Health 2015;12:418-23.

10 Andersen LB, Lawlor DA, Cooper AR, et al. Physical fitness in relation to transport to school in adolescents: the Danish youth and sports study. Scand J Med Sci Sports 2009;19:406-11.

11 Celis-Morales CA, Lyall DM, Welsh P, et al. Association between active commuting and incident cardiovascular disease, cancer, and mortality: prospective cohort study. BMJ 2017;357:j1456.

12 Cooper AR, Wedderkopp N, Wang H, et al. Active travel to school and cardiovascular fitness in Danish children and adolescents. Med Sci Sports Exerc 2006;38:1724-31.

13 Von Elm E, Altman DG, Egger M, et al. STROBE initiative. The strengthening the reporting of observational studies in epidemiology (STROBE) statement: guidelines for reporting observational studies. $\mathrm{J}$ Clin Epidemiol 2008;4:344-9.

14 Andersen LB, Wedderkopp N, Kristensen P, et al. Cycling to school and cardiovascular risk factors: a longitudinal study. J Phys Act Health 2011;8:1025-33.

15 Panter J, Costa S, Dalton A, et al. Development of methods to objectively identify time spent using active and motorised modes of travel to work: how do self-reported measures compare? Int J Behav Nutr Phys Act 2014;11:116.

16 Fjeldsoe BS, Marshall AL, Miller YD. Measurement properties of the Australian women's activity survey. Med Sci Sports Exerc 2009;41:1020-33.
17 Fogelholm M, Malmberg J, Suni J, et al. International physical activity questionnaire: validity against fitness. Med Sci Sports Exerc 2006;38:753-60.

18 Santtila M, Häkkinen K, Pihlainen K, et al. Comparison between direct and predicted maximal oxygen uptake measurement during cycling. Mil Med 2013;178:234-8.

19 Steene-Johannessen J, Anderssen SA, Kolle E, et al. Low muscle fitness is associated with metabolic risk in youth. Med Sci Sports Exerc 2009;41:1361-7.

20 Oja P, Mänttäri A, Heinonen A, et al. Physiological effects of walking and cycling to work. Scand J Med Sci Sports 1991;1:151-7.

21 Gram AS, Bladbjerg E-M, Quist JS, et al. Anti-Inflammatory effects of active commuting and leisure time exercise in overweight and obese women and men: a randomized controlled trial. Atherosclerosis 2017;265:318-24.

22 Flint E, Webb E, Cummins S. Change in commute mode and bodymass index: prospective, longitudinal evidence from UK Biobank. Lancet Public Health 2016;1:e46-55.

23 Møller NC, Østergaard L, Gade JR, et al. The effect on cardiorespiratory fitness after an 8-week period of commuter cycling--a randomized controlled study in adults. Prev Med 2011:53:172-7.

24 Quist JS, Rosenkilde M, Petersen MB, et al. Effects of active commuting and leisure-time exercise on fat loss in women and men with overweight and obesity: a randomized controlled trial. Int $J$ Obes 2018;42:469-78.

25 Rosenkilde M, Petersen MB, Gram AS, et al. The GO-ACTIWE randomized controlled trial - An interdisciplinary study designed to investigate the health effects of active commuting and leisure time physical activity. Contemp Clin Trials 2017;53:122-9. 